\title{
PERMISIF DALAM SISTEM PENGENDALIAN MANAJEMEN (STUDI KASUS DALAM UD SINAR MOTOR)
}

\author{
Carissa Juanita Saputra \\ Universitas Surabaya \\ Juanitacarissa@gmail.com \\ Bonnie Soeherman \\ Universitas Surabaya \\ Bonnie_s@staff.ubaya.ac.id
}

\begin{abstract}
This study aims to determine the impact of permissiveness in the management control system. Management control system cannot be implemented because of permissiveness that gives looseness in management control system. Problems occur are in the form of attendance and attendance of employees, punishment is less applied with firm, tolerance in recruit employees. Writing this thesis is included in applied research where the author hopes with the writing of this thesis can assist in providing recommendations and suggestions related to management control system in Sinar Motor. The research method used is by interview, observation and data analysis. At this writing will be discussed about the management system of the company's management Sinar Motor include action control, result control, personnel control and cultural control. However, the management control system has not been able to perform well due to permissive generated from the nature of the owner who did not bear, pity and trust. To minimize the problem, the authors provide recommendations in the form of limitation of tolerance that can be done by the owner for each problem. With some recommendations are expected to improve management control system UD Sinar Motor.
\end{abstract}

Keywords: Management Control System; Kinship; Unwilling; Permissive; Tolerance.

\section{PENDAHULUAN}

Banyak faktor yang mempengaruhi kinerjaperusahaan seperti pemimpinyang ingin menjalin hubungan yang baik dengan bawahan, memiliki rasa takut yang berlebihan dan takut untuk mengambil resiko. Dalam menjalankan proses bisnis perusahaan, hubungan antara pemimpin dengan bawahan bisa menjadi salah satu faktor penting, namun tidak menutup kemungkinan bahwa dalam mengutamakan hubungan tersebut bisa berdampak baik positif atau berdampak negatif. Berdampak negatif seperti akibat dekatnya hubungan pemimpin dengan bawahan menyebabkan pemimpin menjadi memiliki rasa tidak tega, permisif, kasihan dan percaya terhadap karyawan yang menyebabkan sistem pengendalian manajemen yang sudah diaplikasikan 
menjadi longgar, banyak tindakan karyawan yang dimaafkan, ditoleransi dan dimaklumi. Pada umumnya, kelonggaran dalam penerapan pengendalian ini mendorong para karyawan memiliki loyalitas tinggi seperti karyawan memiliki masa kerja yang lebih tinggi di perusahaan dibandingkan dengan menerapkan sistem pengendalian yang professional seperti perusahaan publik akan tetapi tidak menimbulkan hubungan yang nyaman antara karyawan seperti pada perusahaan keluarga. Dalam menjalankan perusahaan, hubungan antara pemimpin dengan bawahan bisa menjadi salah satu faktor penting, namun tidak menutup kemungkinan bahwa dalam mengutamakan hubungan tersebut bisa berdampak negatif bagi perusahaan. Beberapa stigma yang menyatakan bahwa perusahaan keluarga sering tidak professional, tidak bisa memisahkan kepentingan keluarga dan kepentingan bisnis, lebih mengutamakan hubungan keluarga daripada kinerja, dan memiliki sistem pengendalian yang tidak terkontrol.

Dalam perusahaan, kinerja perusahaan akan menjadi lebih baik apabila setiap aspek dapat dikontrol, hal ini bertujuan untuk meminimalisir tindak kecurangan ataupun kegagalan sehingga celah perusahaan untuk mengalami kerugian semakin sedikit. Berbeda dengan perusahaan keluarga yang lebih mengedepankan hubungan kekeluargaan dalam bekerja, sehingga cenderung lebih memilih menjalin hubungan baik diantara para karyawan daripada harus menimbulkan hubungan yang tidak nyaman dengan karyawan.

Sistem pengendalian manajemen sangatlah penting dalam suatu perusahaan baik perusahaan dengan skala besar maupun kecil. Tanpa sistem pengendalian manajemen akan memunculkan lack of directions, motivational problems dan personal limitations. Menurut Simons (2002) dalam Acquaah (2013) menyatakan bahwa sistem pengendalian manajemen adalah formal, rutinitas berbasis informasi dari prosedur yang digunakan manajer untuk mempertahankan atau mengubah pola aktivitas organisasi.

Pada UD Sinar Motor pemimpinnya mengutamakan hubungan kekeluargaan yang baik dengan karyawannya. Namun karena mengutamankan hubungan yang baik tersebut, pemimpin dalam menjalankan kegiatan perusahaan terutama terkait sistem pengendalian manajemennya penuh dengan rasa tidak tega, permisif, takut, kasihan dan percaya kepada karyawannya sehingga menyebabkan sistem pengendalian manajemen yang dilakukan perusahaan menjadi sangat luwes, longgar, penuh toleransi dan memaafkan. Keluwesan dalam sistem pengendalian manajemen perusahaan ini tidak membuat karyawan perusahaan memiliki tanggung jawab yang tinggi. Hal 
tersebut dapat dilihat dari tingkah laku karyawannya seperti: suka terlambat datang kerja, melakukan pencurian, produktifitas karyawan yang kurang maksimal dan lain sebagainya. Dikarenakan pemimpin yang tidak tega, kasihan dan percaya terhadap karyawannya menimculkan sifat permisif pada pemilik dalam melakukan pengendalian terhadap tingkah laku karyawan tersebut.

Peneliti ingin mencari faktor-faktor penyebab yang menyebabkan tidak efektifnya sistem pengendalian manajemen dan memberikan rekomendasi terkait sistem pengendalian manajemen yang dapat dilakukan oleh perusahaan yang dapat direkomendasikan untuk menyelesaikan permasalahan yang terkait dengan sistem pengendalian manajemen dan kinerja perusahaan.

\section{TELAAH TEORITIS}

Sistem pengendalian manajemen menurut Kenneth A. Merchant dan Wim A. Van Der Stede (2007) menyatakan bahwa pengendalian manajemen merupakan fungsi penting organisasi dan menurut Supriyono (2000;19) dalam bukunya mendefinisikan sistem pengendalian manajemen adalah sistem yang bertujuan untuk mempertahankan atau memelihara kondisi yang diinginkan atau mencapai tujuan yang diinginkan. Kegagalan dalam melakukan kegiatan pengendalian manajemen berdampak pada kerugian financial, menghancurkan reputasi perusahaan, dan berujung pada kegagalan organisasi itu sendiri.Kenneth A. Merchant dan Wim A. Van Der Stede (2007) menyatakan bahwa terdapat tiga penyebab munculnya masalah terkait sistem pengendalian manajemen yaitu: Lack of Direction, Motivational Problems dan Personal Limitations.

Menurut Merchant dan Van der Stede (2007) terdapat empat bentuk sistem pengendalian manajemen yaitu: results controls, action controls, personnel controls dan culture controls.

1. Result Control: Pengendalian ini menghendaki organisasi untuk memberikan rewards kepada karyawan yang menghasilkan hasil terbaik sesuai dengan tujuan organisasi.

2. Action Control: melibatkan pengambilan langkah-langkah untuk memastikan bahwa karyawan bertindak sesuai dengan kepentingan terbaik organisasi

3. Personnel Control: bentuk pengendalian yang memungkinkan seseorang untuk mengendalikan diri sendiri. 
4. Cultural Control: mendorong para karyawan untuk saling mengendalikan antar satu orang dengan orang lainnya.

Keempat bentuk sistem pengendalian manajemen memiliki kemampuan untuk mengatasi permasalahan sistem pengendalian manajemen sebagai berikut:

Tabel 1. Peranan Result Controls

\begin{tabular}{|l|c|c|c|}
\hline \multirow{2}{*}{ Control Types } & \multicolumn{3}{|c|}{ Control Problems } \\
\cline { 2 - 4 } & $\begin{array}{c}\text { Lack of } \\
\text { direction }\end{array}$ & $\begin{array}{c}\text { Motivational } \\
\text { Problems }\end{array}$ & $\begin{array}{c}\text { Personal } \\
\text { Limitations }\end{array}$ \\
\hline Result Controls & & & \\
\hline $\begin{array}{l}\text { Result } \\
\text { Accountability }\end{array}$ & $\mathrm{X}$ & $\mathrm{X}$ & \\
\hline
\end{tabular}

Sumber: Merchant dan Van der Stede, 2007

Tabel 2. Peranan Action Controls

\begin{tabular}{|c|c|c|c|}
\hline \multirow{2}{*}{$\begin{array}{l}\text { TIPE ACTION } \\
\text { CONTROL }\end{array}$} & \multicolumn{3}{|c|}{ Control Problem } \\
\hline & $\begin{array}{c}\text { Lack of } \\
\text { Direction }\end{array}$ & $\begin{array}{c}\text { Motivational } \\
\text { Problem }\end{array}$ & $\begin{array}{c}\text { Personnal } \\
\text { Limitations }\end{array}$ \\
\hline Behavioral Constraints & & $\mathrm{X}$ & \\
\hline Preaction Reviews & $\mathrm{X}$ & $\mathrm{X}$ & $\mathrm{X}$ \\
\hline Action Accountability & $\mathrm{X}$ & $\mathrm{X}$ & $\mathrm{X}$ \\
\hline Redudancy & & $\mathrm{X}$ & $\mathrm{X}$ \\
\hline
\end{tabular}

Sumber: Merchant dan Van der Stede, 2007 
Tabel 3. Peranan Personnel Controls dan Cultural Controls

\begin{tabular}{|l|c|c|c|}
\hline \multicolumn{1}{|c|}{ Personnel Controls } & $\begin{array}{c}\text { Lack of } \\
\text { direction }\end{array}$ & $\begin{array}{c}\text { Motivational } \\
\text { Problems }\end{array}$ & $\begin{array}{c}\text { Personnel } \\
\text { Limitations }\end{array}$ \\
\hline Seleksi dan Penempatan & $\mathrm{X}$ & $\mathrm{X}$ & $\mathrm{X}$ \\
\hline $\begin{array}{l}\text { Pelatihan yang disiapkan } \\
\text { Untuk karyawan }\end{array}$ & $\mathrm{X}$ & $\mathrm{X}$ & $\mathrm{X}$ \\
\hline $\begin{array}{l}\text { Perancangan tugas (job } \\
\text { Design) yang baik }\end{array}$ & & & $\mathrm{X}$ \\
\hline Cultural controls & $\mathrm{X}$ & $\mathrm{X}$ \\
\hline $\begin{array}{l}\text { Penghargaan berbasis } \\
\text { Kelompok(group-based } \\
\text { rewards) }\end{array}$ & $\mathrm{X}$ & $\mathrm{X}$ \\
\hline $\begin{array}{l}\text { Rotasi tugas (intra- } \\
\text { Organizational transfers) }\end{array}$ & & & \\
\hline $\begin{array}{l}\text { Pengaturan fisik dan sosial } \\
\text { (physical and social } \\
\text { arrangements) }\end{array}$ & & & \\
\hline $\begin{array}{l}\text { Pemberian contoh dari } \\
\text { atasan (tone at the top) }\end{array}$ & $\mathrm{X}$ & & \\
\hline
\end{tabular}

Sumber: Merchant dan Van der Stede, 2007

Selain itu, peneliti juga menggunakan teori mengenai ketakutan akan kegagalan yang terdiri dari aspek-aspek takut akan kegagalan dan faktor-faktor pemicu takut akan kegagalan. Aspek-aspek ketakutan akan kegagalan menurut Conroy (dalam Nainggolan, 2007) antara lain: (1) Ketakutan akan dialaminya penghinaan dan rasa malu, (2) Ketakutan akan penurunan estimasi diri (self-estimate) individu, (3) Ketakutan akan hilangnya pengaruh social, (4) Ketakutan akan ketidakpastian masa depan, dan (5) Ketakutan akan mengecewakan orang yang penting baginya. Sedangkan terkait dengan faktor pemicu rasa takut akan kegagalan antara lain: pengalaman negative masa lalu dan pikiran yang tidak rasional.

\section{METODE PENELITIAN}

Tujuan utama penelitian ini adalah lebih ke explanatory research untuk memberikan pemahaman terkait evaluasi sistem pengendalian manajemen pada perusahaan UD Sinar Motor yang dipengaruhi faktor permisif, dimana pada UD Sinar Motor tersebut sistem pengendalian manajemennya tidak bekerja dengan baik akibat faktor permisif sehingga mengalami penurunan 
kinerja perusahaan. Sehingga tujuan penelitian ini adalah untuk merekomendasikan sistem pengendalian manajemen yang dapat dilakukan perusahaan dengan atau tidak merubah faktor permisif tersebut, dan hal-hal lain yang dapat direkomendasikan dalam menyelesaikan permasalahan yang dihadapi perusahaan terkait sistem pengendalian manajemen yang menurunkan kinerja perusahaan.

Pada penelitian ini, pertama-tama peneliti akan melihat dari gaya kepemimpinan dari pemilik tersebut. Dengan melihat dari gaya kepemimpinan pemilik maka peneliti dapat mengetahui karakteristik pemilik dalam menjalankan bisnisnya. Kemudian kedua dengan melihat kondisi sistem pengendalian manajemen yang sudah diaplikasikan pada perusahaan tersebut. Ketiga adalah dengan mengindentifikasi permasalahan yang terjadi pada UD Sinar Motor dalam masalah sistem pengendalian manajemen. Terakhir, dengan sudah diindentifikasi permasalahan yang terjadi beserta meneliti sistem pengendalian manajemen dan gaya kepemimpinan dari pemilik maka peneliti dapat memberikan rekomendasi agar kinerja perusahaan dapat ditingkatkan.

Penelitian ini menggunakan berbagai metode pengumpulan data antara lain wawancara dan observasi dan analisis dokumen. Wawancara dilakukan kepada pemilik UD Sinar Motor dan beberapa karyawan perusahaan. Wawancara dilakukan dengan metode semi- structure. Observasi dilakukan dengan cara datang ke perusahaan selama jam kerja. Sedangkan untuk analisis dokumen dilakukan pada dokumen nota penjualan, nota supplier dan buku absensi. Setelah mengumpulkan data-data tersebut, pemilik menganalisis data tersebut dengan dikaitkan landasan teori yang digunakan untuk menjawab mini research question.

\section{HASIL}

UD Sinar Motor adalah perusahaan yang bergerak dalam bidang perbaikan dan pemasangan sparepart dan aksesoris mobil. UD Sinar Motor pertama kali berdiri pada tahun 1985 dengan pernah mengalami jatuh bangun. Saat ini UD Sinar Motor berada di jalan Krukah Timur No. 49 Surabaya. UD Sinar Motor memiliki visi "memperoleh keuntungan dan mampu mensejahterakan seluruh pelaku perusahaan” dengan didukung oleh misinya yaitu selalu memberikan pelayanan yang terbaik baik sebelum dan sesudah penjualan dan menjaga relasi dengan pelanggan. 
UD Sinat Motor tidak memiliki pemahaman mengenai sistem pengendalian manajemen, namun peneliti dapat mencoba mengidentifikasi bentuk sistem pengendalian manajemen yang diaplikasikan UD Sinar Motor sebagai berikut:

Tabel 4. Sistem Pengendalian Manajemen di UD Sinar Motor

\begin{tabular}{|c|c|c|c|}
\hline \begin{tabular}{l|l} 
Result \\
Controls \\
\end{tabular} & Action Control & $\begin{array}{c}\text { Personnel } \\
\text { Controls } \\
\end{array}$ & $\begin{array}{l}\text { Cultural } \\
\text { Control }\end{array}$ \\
\hline \multirow[t]{2}{*}{$\begin{array}{l}\text { Reward: } \\
\text { materi dan } \\
\text { verbal }\end{array}$} & $\begin{array}{l}\text { Behaviour Constraints: } \\
\text { Prosedur penggunaan alat, } \\
\text { tanda pada nota supplier dan } \\
\text { nota penjualan, prosedur } \\
\text { uang bensin dan kunci } \\
\text { kendaraan }\end{array}$ & $\begin{array}{l}\text { Seleksi dan } \\
\text { Penempatan }\end{array}$ & \multirow[t]{2}{*}{$\begin{array}{l}\text { Physical dan } \\
\text { Social } \\
\text { Arrangement: } \\
\text { Pemberian } \\
\text { fasilitas yang } \\
\text { memudahkan } \\
\text { divisi, } \\
\text { menanamkan } \\
\text { pola pikir, } \\
\text { gotong royong }\end{array}$} \\
\hline & $\begin{array}{l}\text { Preaction review: Seluruh } \\
\text { aktivitas memerlukan ijin } \\
\text { pemilik }\end{array}$ & $\begin{array}{l}\text { Training: } \\
\text { Pelatihan melalui } \\
\text { pengalaman } \\
\text { langsung }\end{array}$ & \\
\hline $\begin{array}{l}\text { Target: Kerajinan } \\
\text { dan kesergapan }\end{array}$ & $\begin{array}{l}\text { Action accountability: } \\
\text { Pegawasan kepada semua } \\
\text { divisi } \\
\text { Redudancy: } \\
\text { Setiap divisi memiliki } \\
\text { sebagian tugas yang sama }\end{array}$ & $\begin{array}{l}\text { Job Design : } \\
\text { Tugas Karyawan } \\
\text { disesuaikan } \\
\text { kemampuan } \\
\text { individu dari } \\
\text { penilaian pemilik }\end{array}$ & $\begin{array}{l}\text { Tone at the top: } \\
\text { Gotong royong, } \\
\text { disiplin }\end{array}$ \\
\hline
\end{tabular}

\section{PEMBAHASAN}

Setelah melihat dari aplikasi sistem pengendalian manajemen, peneliti dapat melihat faktor-faktor yang memicu permasalahan terjadi. Beberapa dari sistem pengendalian manajemen diatas tidak dapat berjalan dengan baik akibat dari rasa kasihan, tidak tega dan percaya terhadap karyawan yang menimbulkan sifat permisif. Dari permasalahan tersebut, pemilik mencari akar permasalahan dan dampak yang terjadi akibat dari faktor tersebut. Berdasarkan analisis tersebut, barulah peneliti dapat memberikan rekomendasi perbaikan sistem pengendalian manajemen guna meminimalisir permasalahan yang ada. 
Tabel 5. Implikasi Temuan Masalah dan Rekomendasi

\begin{tabular}{|c|c|c|c|c|}
\hline $\begin{array}{l}\text { Temuan } \\
\text { Masalah }\end{array}$ & $\begin{array}{c}\text { Masalah } \\
\text { Sistem } \\
\text { Pengendalian } \\
\text { Manajemen }\end{array}$ & Penyebab & Dampak & Rekomendasi \\
\hline $\begin{array}{l}\text { Kepercaya } \\
\text { an atas hasil } \\
\text { kerja } \\
\text { karyawan }\end{array}$ & $\begin{array}{l}\text { Lack of } \\
\text { direction dan } \\
\text { lack of } \\
\text { motivational }\end{array}$ & $\begin{array}{l}\text { - Pemakluman } \\
\text { pemilik } \\
\text { dengan } \\
\text { menganggap } \\
\text { karyawan } \\
\text { adalah } \\
\text { manusia yang } \\
\text { bisa berbuat } \\
\text { salah } \\
\text { - Kepercayaan } \\
\text { terhadap } \\
\text { karyawannya } \\
\text { karena sudah } \\
\text { bekerja lama }\end{array}$ & $\begin{array}{l}\text { - Kepercayaan } \\
\text { tersebut } \\
\text { membuat } \\
\text { pemilik jarang } \\
\text { melakukan } \\
\text { evaluasi kerja } \\
\text { - Memungkinka } \\
\text { n karyawan } \\
\text { bingung } \\
\text { dengan hasil } \\
\text { kerja mereka, } \\
\text { dengan asumsi } \\
\text { sudahb ekerja } \\
\text { dengan } \\
\text { maksimal. } \\
\text { - Karena tidak } \\
\text { ada } \\
\text { pengawasan } \\
\text { membuat } \\
\text { karyawan tidak } \\
\text { termotivasi } \\
\text { bekerja lebih } \\
\text { baik }\end{array}$ & $\begin{array}{l}\text { - Melakukan } \\
\text { evaluasi } \\
\text { kerja baik } \\
\text { saat } \\
\text { pertengahan } \\
\text { hingga } \\
\text { akhir proses } \\
\text { pemasangan } \\
\text { (dengan } \\
\text { menanyakan } \\
\text { kendala, } \\
\text { kesulitan } \\
\text { dan bantuan } \\
\\
\text { apa yang } \\
\text { dibutuhkan } \\
\text { karyawan) }\end{array}$ \\
\hline $\begin{array}{l}\text { Pengawas an } \\
\text { yang minim } \\
\text { terhadap } \\
\text { biaya } \\
\text { operasional } \\
\text { perusahaan }\end{array}$ & $\begin{array}{l}\text { Lack of } \\
\text { direction }\end{array}$ & \begin{tabular}{|l} 
- Tidak tega \\
dalam \\
mengingatkan \\
karyawan \\
untuk lebih \\
meminimalkan \\
biaya \\
- Memaklumi \\
bahwa \\
karyawan \\
adalah manusia \\
bisa salah dan \\
merasa kasihan \\
dan tidak tega \\
untuk \\
mengingatkan \\
- Tidak ada \\
pencatatan
\end{tabular} & $\begin{array}{l}\text { - Beberapa biaya } \\
\text { operasional } \\
\text { meningkat } \\
\text { dari biasanya } \\
\text { - Kemungkinan } \\
\text { ketidaktahuan } \\
\text { pemilik dalam } \\
\text { peningkatan } \\
\text { biaya pada } \\
\text { beberapa biaya } \\
\text { yang sudah } \\
\text { ditetapkan }\end{array}$ & $\begin{array}{l}\text { - Memperketat } \\
\text { penggunaan } \\
\text { biaya } \\
\text { operasional } \\
\text { dengan } \\
\text { dilakukan } \\
\text { pengawasan } \\
\text { - Mencatat } \\
\text { secara rinci } \\
\text { siapa yang } \\
\text { menggunakan, } \\
\text { keperluan apa, } \\
\text { kapan } \\
\text { digunakan, dan } \\
\quad \text { tempat } \\
\text { tujuan. }\end{array}$ \\
\hline
\end{tabular}




\begin{tabular}{|c|c|c|c|c|}
\hline & & biaya & & \\
\hline $\begin{array}{ll}\text { Tidak } & \text { ada } \\
\text { harga } & \text { jual } \\
\text { pasti } & \end{array}$ & $\begin{array}{l}\text { Lack of } \\
\text { direction }\end{array}$ & $\begin{array}{l}\text { - Keinginan } \\
\text { pemilik untuk } \\
\text { terjadi transaksi } \\
\text { pembelian } \\
\text { sehingga } \\
\text { keuntungan } \\
\text { tersebut bisa } \\
\text { digunakan untuk } \\
\text { karyawan dan } \\
\text { dirinya sendiri } \\
\text { - Rasa tidak } \\
\text { enak dan } \\
\text { kasihan } \\
\text { terhadap } \\
\text { karyawan } \\
\text { apabila tidak } \\
\text { mendapatkan } \\
\text { penghasilan } \\
\text { untuk dibawa } \\
\text { pulang }\end{array}$ & $\begin{array}{l}\text { - Sales tidak } \\
\text { dapat mejual } \\
\text { barang dengan } \\
\text { leluasa } \\
\text { dikarenakan } \\
\text { tidak adanya } \\
\text { harga jual pasti } \\
\text { - Sales cukup } \\
\text { sering harus } \\
\text { menanyakan } \\
\text { harga yang } \\
\text { dijual kepada } \\
\text { pemilik }\end{array}$ & $\begin{array}{l}\text { - Pembuatan list } \\
\text { harga jual } \\
\text { umum, apabila } \\
\text { yang datang } \\
\text { adalah } \\
\text { karyawan } \\
\text { khusus atau } \\
\text { meminta } \\
\text { negosiasi baru } \\
\text { sales dapat } \\
\text { berkonsultasi } \\
\text { kepada pemilik }\end{array}$ \\
\hline $\begin{array}{l}\text { Toleransi } \\
\text { dalam } \\
\text { penerapan } \\
\text { punishment }\end{array}$ & $\begin{array}{l}\text { Lack of } \\
\text { motivational }\end{array}$ & $\begin{array}{l}\text { - Ketakutan } \\
\text { pemilik apabila } \\
\text { terjadi konflik } \\
\text { dengan } \\
\text { karyawannya } \\
\text { - Rasa kasihan } \\
\text { pemilik terhadap } \\
\text { karyawan } \\
\text { bersangkutan } \\
\text { - Rasa takut } \\
\text { kehilangan } \\
\text { karyawan } \\
\text { - Pemilik } \\
\text { memaklumi } \\
\text { tindakan } \\
\text { karyawan } \\
\text { sehingga } \\
\text { dimaafkan dan } \\
\text { ditoleransi }\end{array}$ & $\begin{array}{l}\text { - Karena komproni } \\
\text { yang terlalu besar } \\
\text { dari pemilik, } \\
\text { membuat } \\
\text { karyawan tidak } \\
\text { termotivasi } \\
\text { bekerja dengan } \\
\text { lebih baik dan } \\
\text { tidak takut } \\
\text { dengan } \\
\text { konsekuensi } \\
\text { dikarenakan } \\
\text { sering dimaafkan }\end{array}$ & $\begin{array}{l}\text { - Menetapkan } \\
\text { punishment } \\
\text { yang sesuai } \\
\text { dengan } \\
\text { kesalahan yang } \\
\text { dilakukan } \\
\text { - Karyawan } \\
\text { dengan } \\
\text { dituliskan } \\
\text { secara formal } \\
\text { - Punishment } \\
\text { dilakukan } \\
\text { dengan } \\
\text { diberikan } \\
\text { teguran } \\
\text { peringatan } \\
\text { terlebih dahulu } \\
\text { dan dilakukan } \\
\text { secara private } \\
\text { untuk menjaga } \\
\text { hargadiri } \\
\text { karyawan }\end{array}$ \\
\hline
\end{tabular}

Jurnal Akuntansi dan Teknologi Informasi (JATI) Vol. 13 Tahun 2019 


\begin{tabular}{|c|c|c|c|c|}
\hline & & & & $\begin{array}{l}\text { - Melakukan } \\
\text { training atau } \\
\text { meeting }\end{array}$ \\
\hline $\begin{array}{l}\text { Toleransi } \\
\text { atas } \\
\text { kehadiran } \\
\text { dan } \\
\text { kedatangan } \\
\text { karyawan }\end{array}$ & $\begin{array}{l}\text { Lack of } \\
\text { motivational }\end{array}$ & $\begin{array}{l}\text { - Pemilik } \\
\text { memaklumi } \\
\text { tindakan } \\
\text { karyawan } \\
\text { dikarenakan } \\
\text { situasi } \\
\text { karyawannya } \\
\text { - Rasa tidak enak } \\
\text { karena } \\
\text { beberapa } \\
\text { karyawan } \\
\text { dianggap } \\
\text { memiliki jasa } \\
\text { yang besar } \\
\text { dalam } \\
\text { perusahaan } \\
\text { Pemilik tidak } \\
\text { ingin } \\
\text { hubungannya } \\
\text { dengan } \\
\text { karyawan } \\
\text { menjadi rusak }\end{array}$ & $\begin{array}{l}\text { - Karyawan } \\
\text { menjadi sering } \\
\text { tidak masuk kerja } \\
\text { dengan rata-rata } \\
\text { sebulan 3-4x } \\
\text { (terutama } \\
\text { karyawan dengan } \\
\text { gaji bulanan) } \\
\text { - Karyawan } \\
\text { menjadi sering } \\
\text { dating terlambat } \\
\text { dari jadwal yang } \\
\text { sudah ditetapkan }\end{array}$ & $\begin{array}{l}\text { - Mengubah } \\
\text { gaji bulanan } \\
\text { menjadi } \\
\quad \text { gaji harian } \\
\text { - Melakukan } \\
\text { teguran } \\
\quad \text { bagi yang } \\
\text { melakukan } \\
\text { pelanggaran } \\
\text { - Melakukan } \\
\text { pengawasan } \\
\text { dengan } \\
\text { menggunakan } \\
\text { absensi } \\
\text { karyawan } \\
\text { - Mengubah } \\
\text { jadwal } \\
\text { kedatangan } \\
\text { karyawan } \\
\text { sesuai dengan } \\
\text { pemilik } \\
\text { - Perubahan } \\
\text { dari } \\
\text { pemiliknya } \\
\text { sendiri dengan } \\
\text { datang lebih } \\
\text { awal }\end{array}$ \\
\hline $\begin{array}{l}\text { Tidak } \\
\text { berfokus } \\
\text { kepada } \\
\text { pekerjaan } \\
\text { utama }\end{array}$ & $\begin{array}{l}\text { Lack of } \\
\text { motivational }\end{array}$ & $\begin{array}{l}\text { - Keinginan } \\
\text { pemilik untuk } \\
\text { terjadi transaksi } \\
\text { pembelian } \\
\text { sehingga } \\
\text { keuntungan } \\
\text { tersebut } \\
\quad \text { bisa } \\
\text { digunakan } \\
\text { untuk karyawan } \\
\text { dan dirinya } \\
\text { sendiri } \\
\text { - Rasa tidak enak } \\
\text { dan kasihan }\end{array}$ & $\begin{array}{l}\text { Pekerjaan } \\
\text { sampingan } \\
\text { tersebut bukan } \\
\text { keahlian } \\
\text { karyawan, } \\
\text { memakan waktu } \\
\text { yang lama dan } \\
\text { tenaga membuat } \\
\text { karyawan tidak } \\
\text { termotivasi saat } \\
\text { ditugaskan } \\
\text { pekerjaan } \\
\text { sampingan } \\
\text { tersebut dan } \\
\text { karyawan merasa }\end{array}$ & $\begin{array}{l}\text { - Memikirkan } \\
\text { kuantias } \\
\text { pekerjaan } \\
\text { sampingan yang } \\
\text { dapat diambil } \\
\text { dengan } \\
\text { memikirkan } \\
\text { kemampuan } \\
\text { karyawannya } \\
\text { - Pemberian } \\
\text { bonus yang } \\
\text { setimpal } \\
\text { atas hasil kerja } \\
\text { karyawan }\end{array}$ \\
\hline
\end{tabular}




\begin{tabular}{|c|c|c|c|c|}
\hline & & $\begin{array}{l}\text { terhadap } \\
\text { karyawan } \\
\text { apabila tidak } \\
\text { mendapatkan } \\
\text { penghasilan } \\
\text { untuk dibawah } \\
\text { pulang }\end{array}$ & kelelahan & \\
\hline $\begin{array}{l}\text { Toleransi } \\
\text { terhadap } \\
\text { target } \\
\text { karyawan }\end{array}$ & $\begin{array}{l}\text { Lack of } \\
\text { motivational }\end{array}$ & $\begin{array}{l}\text { - Rasa kasihan } \\
\text { pemilik dalam } \\
\text { pemberian } \\
\text { target yang sulit } \\
\text { terhadap } \\
\text { karyawannya } \\
\text { - Apabila } \\
\text { karyawan tidak } \\
\text { memenuhi } \\
\text { kriteria tersebut } \\
\text { dimaklumi } \\
\text { dengan } \\
\text { anggapan } \\
\text { bahwa } \\
\text { karyawan } \\
\text { adalah manusia } \\
\text { punya rasa } \\
\text { malas }\end{array}$ & $\begin{array}{l}\text { - Karyawan } \\
\text { berkesempatan } \\
\text { memperoleh gaji } \\
\text { penuh asal“hadir } \\
\text { bekerja” tanpa } \\
\text { adanya target } \\
\text { kerja } \\
\text { - Target kerja yang } \\
\text { diberikan kepada } \\
\text { karyawan sangat } \\
\text { sederhana } \\
\text { dikarenakan } \\
\text { beberapa faktor }\end{array}$ & $\begin{array}{l}\text { - Pembuatan } \\
\text { target kerja } \\
\text { yang lebih } \\
\text { spesifik } \\
\text { dengan } \\
\text { menetapkan } \\
\text { tujuan dan } \\
\text { dikerjakan } \\
\text { secara } \\
\text { bersama-sama }\end{array}$ \\
\hline $\begin{array}{l}\text { Toleransi } \\
\text { dalam } \\
\text { recruit } \\
\text { karyawan }\end{array}$ & $\begin{array}{l}\text { Lack of } \\
\text { motivational } \\
\text { dan Personnel } \\
\text { Limitations }\end{array}$ & $\begin{array}{l}\text { - Rasa kasihan } \\
\text { pemilik } \\
\text { terhadap calon } \\
\text { karyawan baru } \\
\text { dengan } \\
\text { pertimbanan } \\
\text { alasan } \\
\text { karyawannya } \\
\text { (sopan,baik, } \\
\text { mau bekerja } \\
\text { dan belajar } \\
\text { serta menjadi } \\
\text { tulang } \\
\text { punggung } \\
\text { keluarga) }\end{array}$ & $\begin{array}{l}\text { - Kemungkinan } \\
\text { karyawan yang } \\
\text { direcruit tidak } \\
\text { memiliki } \\
\text { background yang } \\
\text { dibutuhkan akibat } \\
\text { toleransi pemilik } \\
\text { terhadap } \\
\text { beberapa } \\
\text { karyawan yang } \\
\text { direcruit tidak } \\
\text { memiliki mental } \\
\text { yang baik yang } \\
\text { menyebabkan } \\
\text { mudahnya } \\
\text { kehilangan } \\
\text { motivasi }\end{array}$ & $\begin{array}{l}\text { - “asal anaknya } \\
\text { kelihatan baik } \\
\text { dan mau } \\
\text { bekerja” } \\
\text { dijadikan } \\
\text { sebagai point } \\
\text { tambahan dan } \\
\text { bukan sebagai } \\
\text { point utama } \\
\text { saat merecruit } \\
\text { karyawan } \\
\text { - Melakukan } \\
\text { penilaian } \\
\text { kurang lebih } 3 \\
\text { bulan sebelum } \\
\text { ditetapkan } \\
\text { sebagai } \\
\text { karyawan } \\
\text { tetap }\end{array}$ \\
\hline
\end{tabular}




\begin{tabular}{|c|c|c|c|c|}
\hline $\begin{array}{l}\text { Kelonggaran } \\
\text { dalam } \\
\text { penjagaan } \\
\text { alat dan } \\
\text { kendaraan } \\
\text { perusahaan }\end{array}$ & $\begin{array}{l}\text { Permasalahan } \\
\text { lain }\end{array}$ & $\begin{array}{l}\text { - Kepercayaan } \\
\text { yang besar } \\
\text { bahwa dirinya } \\
\text { dapat } \\
\text { mengawasi } \\
\text { - Kepercayaan } \\
\text { yang besar } \\
\text { terhadap orang- } \\
\text { orang } \\
\text { disekitarnya } \\
\text { dikarenakan } \\
\text { menurut } \\
\text { pemilik mereka } \\
\text { sudah dianggap } \\
\text { sebagai } \\
\text { keluarga }\end{array}$ & $\begin{array}{l}\text { - Memudahkan } \\
\text { karyawan luar } \\
\text { mengambil tanpa } \\
\text { sepengetahuan } \\
\text { karyawan dalam } \\
\text { - Kunci mobil } \\
\text { diletakkan di } \\
\text { dalam mobil yang } \\
\text { memungkinkan } \\
\text { pencurian }\end{array}$ & $\begin{array}{l}\text { - Pengunaan } \\
\text { sumber daya } \\
\text { yang sudah } \\
\text { dimilikioleh } \\
\text { perusahaan } \\
\text { dengan sebaik- } \\
\text { baiknya } \\
\text { - Mengingatkan } \\
\text { untuk segera } \\
\text { mengembalikan } \\
\text { kunci ketempat } \\
\text { yang sudah } \\
\text { disediakan }\end{array}$ \\
\hline $\begin{array}{l}\text { Kelonggaran } \\
\text { dalam } \\
\text { penjagaan } \\
\text { inventory } \\
\text { perusahaan }\end{array}$ & $\begin{array}{l}\text { Permasalahan } \\
\text { lain }\end{array}$ & $\begin{array}{l}\text { - Kepercayaan } \\
\text { yang besar } \\
\text { bahwa dirinya } \\
\text { dapat } \\
\text { mengawasi } \\
\text { - Kepercayaan } \\
\text { yang besar } \\
\text { terhadap } \\
\text { orang-orang } \\
\text { disekitarnya } \\
\text { dikarenakan } \\
\text { menurut } \\
\text { pemilik mereka } \\
\text { sudah dianggap } \\
\text { sebagai } \\
\text { keluarga }\end{array}$ & $\begin{array}{l}\text { - Kemungkinan } \\
\text { sales dan pemilik } \\
\text { tidak mengingat } \\
\text { semua stock } \\
\text { perusahaan } \\
\text { - Inventory } \\
\text { diletakkan } \\
\text { ditempat terbuka } \\
\text { yang } \\
\text { memungkinkan } \\
\text { kemanan } \\
\text { inventory sangat } \\
\text { minim dan mudah } \\
\text { dicuri }\end{array}$ & $\begin{array}{l}\text { - Membuat } \\
\text { liststock } \\
\text { barang baik } \\
\text { daripemilik } \\
\text { sendiri atau } \\
\text { sales atau } \\
\text { kedua belah } \\
\text { pihak } \\
\text { membuat } \\
\text { liststock } \\
\text { - Menggunakan } \\
\text { sumber daya } \\
\text { yang sudah } \\
\text { dimiliki } \\
\text { perusahaan }\end{array}$ \\
\hline
\end{tabular}

\section{KESIMPULAN}

Dari hasil penelitian yang dilakukan terhadap UD Sinar Motor dengan sistem pengendalian manajemen yang sudah diterapkan menunjukan bahwa sistem pengendalian manajemen yang diaplikasikan sudah terbilang cukup baik. Sistem pengendalian manajemen dibuat oleh pemilik dari pandangan pemilik. Namun sistem pengendalian manajemen tersebut tidak berjalan maksimal sesuai yang direcanakan pemilik karena rasa kasihan, tidak tega, percaya dan takut yang 
menimbulkan sifat permisif pada pemilik yang menyebabkan sistem pengendalian manajemen menjadi keluwesan, kelonggaran, toleransi dan memaafkan tindakan karyawan.

Secara garis besar salah satu faktor yang menyebabkan sistem pengendalian manajemen tersebut tidak bekerja dengan baik adalah nilai-nilai kekeluargaan yang ingin diaplikasikan oleh pemilik. Kekeluargaan yang dianut oleh pemilik tidaklah buruk, bahkan bisa menjadi sesuatu yang sangat positif karena mampu menarik hati karyawannya. Hal tersebut dibuktikan dengan sebagian besar karyawannya memiliki loyalitas yang sangat tinggi. Namun pada prakteknya kekeluargaan tersebut menumbuhkan masalah-masalah dalam pengendalian yang diaplikasikan yaitu rasa kasihan, tidak tega, percaya dan takut yang menimbulkan sifat permisif tersebut. Tidak hanya itu, faktor-faktor pendukung adalah masalah biaya. Oleh karena itu diberikan usulan perbaikanperbaikan terkait aplikasi yang sudah ada dan masalah-masalah yang lain dengan tetap mempertimbangkan keinginan pemilik untuk tetap menjaga kekeluargaan tersebut.

\section{DAFTAR PUSTAKA}

Acquaah, Moses 2013, “Management control system, business strategy and performance: a comparative analysis of family and non-family businesses in a transition economy in sub-Saharan Africa", journal of Family Business Strategy4,pp 131-146

Aris Surya Putra. 2013. Implementasi Pengelolaan Media Berbasis Sistem Pengendalian Manajemen Dalam Rangka Meningkatkan Kinerja Pencapaian Sasaran Mutu Warta Ubaya. Jurnal Ilmiah Universitas Surabaya Vol.2 No.1

Bass, B.M. (1985). Leadershipand Performance Beyond Expectations. New York: The Free Press

Djoko Dewantoro. Pengaruh Kekuatan Keluarga Terhadap Kinerja Melalui Sistem Pengendalian Manajemen Pada Perusahaan Keluarga di Surabaya. Jurnal Fakultas Ekonomi dan Bisnis Universitas Airlangga

Longenecker et al.2001. Kewirausahaan Manajemen Usaha Kecil. Buku 1. Jakarta : Salemba Empat Merchant, K.A., dan W.A. Van der Stede. 2007. Management Control System: Performance Measurement, Evaluation, and Incentives, 2nd edition. Prentice Hall: UK

Mariyana, Karolin, Wiyono Pontjoharyo. 2013. Analisis Gaya Kepemimpina Terhadap Penerapan Result Control Pada Divisi Plywood Badan Usaha Keluarga PT.X Di Surabaya. Jurnal Ilmiah Mahasiswa Universitas Surabaya. Vol. 02 No. 01 (2013)

Nur Hidayah, 2016. Analisa Sitem Pengendalian Manajemen untuk Peningkatan Kinerja Manajemen Pada Perusahaan Keluarga (Studi Kasus pada UD.X Sidoarjo) Jurnal jurusan Akuntansi/Fakultas Ekonomi 
Roberth N. Anthony dan Vijay Govindarajan. Management Control System 11th Selemba empat Thomas Sumarsan, 2010. Sistem Pengendalian Manajemen konsep, aplikasi dan pengukuran kinerja

Efferin, Sujokon dan Trevor Hopper, 2007. Management Control, Culture, and Ethnicity in a Chinese Indonesian Company. Sience Direct, pp 223-262

Dwipayana G, Ramadhan KH, 1989. Soeharto: pikiran dan Tindakan Saya. Pt.Citra Lamtoro Gung Persada, Jakarta

Magnis-Suseno (1991) Etika Jawa: Sebuah Analisa Falsafi tentang Kebijaksanaan Hidup Jawa . Penerbit PT. Gramedia Pustaka Utama, Jakarta.

Sarsito, Totok, 2006. Javanese culture as the source of legitimacy for soeharto's government SpringerVerlag, pp1-15 